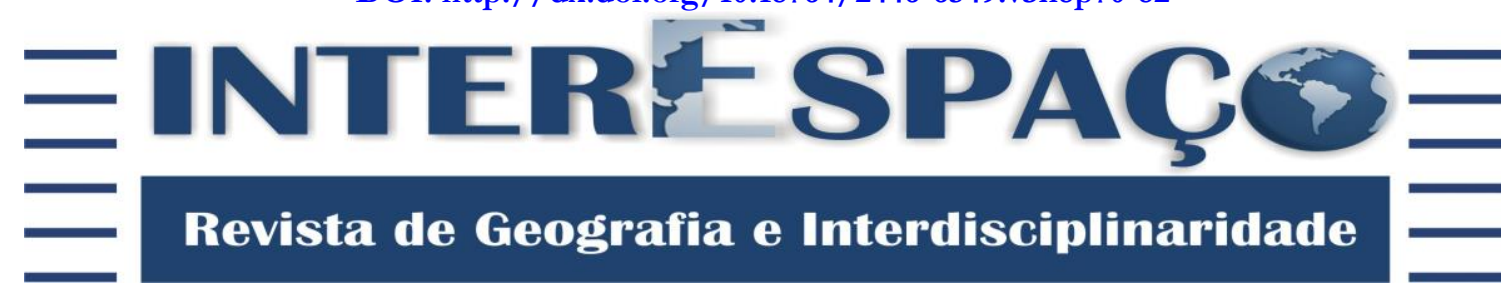

\title{
EDUCAÇÃO GEOGRÁFICA E ARTE EM COMUNIDADES POBRES NO MUNICÍPIO DE PORTO NACIONAL, TOCANTINS, BRASIL
}

\author{
GEOGRAPHIC EDUCATION AND ART IN POOR COMMUNITIES IN THE \\ CITY OF PORTO NACIONAL, TOCANTINS, BRAZIL
}

\section{EDUCACIÓN GEOGRÁFICA Y ARTE EN COMUNIDADES POBRES EN EL MUNICIPIO DE PORTO NACIONAL, TOCANTINS, BRASIL}

\section{Carolina Machado Rocha Busch Pereira}

Doutora em Geografia Humana pela Universidade de São Paulo - USP.

Professora Adjunta do Curso de Geografia da Universidade Federal do Tocantins - UFT. carolinamachado@uft.edu.br

\section{Denis Ricardo Carloto}

Doutor em Geografia Humana pela Universidade de São Paulo - USP.

Professor Adjunto do Curso de Geografia da Universidade Federal do Tocantins - UFT. denis@uft.edu.br

Recebido para avaliação em 02/01/2017; Aceito para publicação em 03/03/2017.

\section{RESUMO}

O presente trabalho tem o objetivo de apresentar os resultados obtidos com o projeto de extensão "Educação geográfica pela arte" desenvolvido na cidade de Porto Nacional, estado do Tocantins situado na região norte do Brasil. O projeto foi desenvolvido na Universidade Federal do Tocantins e foi destinado aos jovens pobres de de 11 a 17 anos, preferencialmente beneficiários do Programa Bolsa Família. Foram realizadas atividades didáticas pedagógicas sobre o ensino de Geografia com foco no estudo sobre a cidade em estreita aproximação com a arte.

Palavras-chave: Extensão Universitária; Oficinas; Geografia; Metodologias.

\section{ABSTRACT}

This paper aims to present the results obtained through the research project Geographic Education and Art developed in the city of Porto Nacional in the state of Tocantins located in the north of Brazil. The project was developed at the Federal University of Tocantins and destined to youngsters from 11 to 17 years old, preferably beneficiaries of "Bolsa Familia" - a Brazilian cash transference program destined to the poorest portion of the population. We accomplished didactic activities about the teaching of Geography focusing the study of the city in close proximity to the art.

Keywords: Outreach university activities; Workshops; Geography; Methodologies.

\section{RESUMEN}

Este estudio tiene como objetivo presentar los resultados obtenidos con el proyecto de extensión "Educación Geográfica para el arte", desarrollado en la ciudad de Porto Nacional, el estado de Tocantins ubicado en la región norte de Brasil. El proyecto fue desarrollado en la Universidad Federal de Tocantins y está destinado a jóvenes de 11 a 17 años, preferiblemente beneficiarios del Programa Bolsa Familia. Actividades educativas pedagógicas se llevaron a cabo en la geografía de enseñanza con enfoque en el estudio de la ciudad en las proximidades con el arte. 
| Educação geográfica e arte em comunidades pobres no município de Porto Nacional, Tocantins, Brasil|

| Carolina Machado Rocha Busch Pereira | Denis Ricardo Carloto |

Palabras clave: Extensión de la Universidad; Talleres; Geografía; Metodologías.

\section{INTRODUÇÃO}

Tendo como princípio orientador a extensão universitária compreendida como processo educativo, cultural e científico que articula o ensino e a pesquisa de forma indissociável é que propusemos o projeto aqui relatado. A extensão universitária é a forma de interação entre a universidade e a comunidade na qual ela está inserida.

O projeto teve como objetivo articular os alunos da Universidade com os adolescentes pobres do município de Porto Nacional/TO em oficinas pedagógicas e culturais. Procurou-se desde o início articular o ensino, a extensão e a pesquisa geográfica utilizando-se de recursos, como pinturas e poemas para dialogar sobre o que é a cidade, o que é o lugar e como estes são provenientes da relação da sociedade com o espaço.

A cidade como conteúdo geográfico tem se apresentado como tema complexo, não só para o ensino fundamental e médio, mas também para a formação de professores em cursos de licenciatura. Considerando a importância do tema "cidade" o debate e a construção das atividades foram iniciados a partir dos conceitos que se relacionam com o conteúdo "cidade", que são: paisagem urbana, modos de vida, cidadania, produção do espaço, territorialidades, cultura, periferia, território usado, entre outros.

Quando elencamos os problemas das cidades em sala de aula, aparecem temas como: lixo, saúde, educação, organização sócio espacial, acessibilidade, entre outros. E todos esses temas se relacionam em grande medida com os conceitos "paisagem urbana, modos de vida, cidadania, produção do espaço, territorialidades, cultura, periferia, território usado", ou seja, com as práticas sociais vividas na cidade. Aos poucos o tema "lixo" vai sendo percebido como elemento importante e transformador do conceito "paisagem urbana". Ou seja, a formação do conceito "paisagem urbana" vai sendo trabalhada com suas relações, aproximações, e referências. O lixo está contido na cidade, transforma a paisagem urbana, e se relaciona com outros temas que juntos formam o arcabouço geográfico necessário para compreender as práticas sociais da vida na cidade. Considerando a aridez do debate teórico e conceitual, as estratégias didáticas eleitas para o projeto foram o uso de diferentes linguagens, e o apoio da arte como recurso articulador de saberes.

Iniciamos os trabalhos com a meta de capacitar os alunos da graduação em Geografia para trabalhar com o cinema, a música, a literatura, e as artes visuais em oficinas culturais voltadas para adolescentes do município de Porto Nacional na faixa etária de 11 a 17 anos, relacionando as expressões artísticas e culturais com o ensino de Geografia. 
| Educação geográfica e arte em comunidades pobres no município de Porto Nacional, Tocantins, Brasil|

| Carolina Machado Rocha Busch Pereira | Denis Ricardo Carloto|

\section{MATERIAIS E MÉTODOS}

O trabalho foi desenvolvido na cidade de Porto Nacional, estado do Tocantins, Brasil, conforme indicado no mapa de localização da área de estudo na Figura 1. O município é considerado polo regional, distante $60 \mathrm{~km}$ da capital, Palmas.

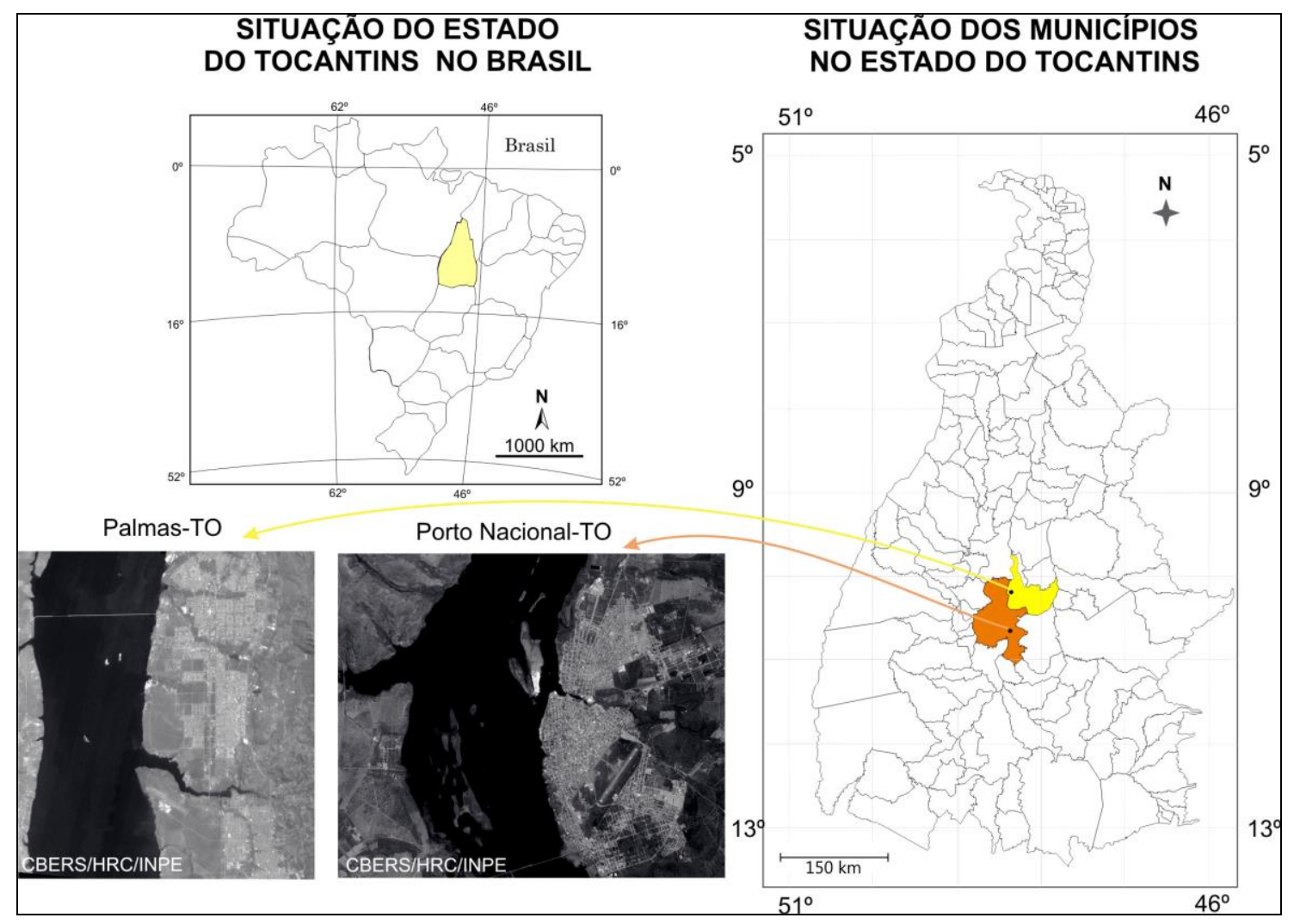

Figura 1 - Área de estudo. Fonte: Elaboração dos autores, 2016.

O município está localizado na Microrregião de Porto Nacional, sendo importante acesso a algumas regiões do Estado e do País. Fundado no início do século XIX, Porto Nacional sempre esteve diretamente ligado histórica e culturalmente ao rio Tocantins. Ao longo daquele século e do século XX, a principal via de acesso era o rio. Embarcações sangravam o Tocantins transportando mercadorias entre Porto Nacional e Belém do Pará. Com a construção da rodovia BR-153, nos anos 1970, o fluxo de pessoas e mercadorias passou para a via terrestre (IPHAN, 2007).

Porto Nacional, cidade centenária do antigo norte goiano, hoje estado do Tocantins, é um lugar no qual a modernidade vem se instalando de forma eficaz, sobretudo nas últimas duas décadas, e tem silenciado os sentidos sociais e temporais ainda permanentes no/do lugar. 
| Educação geográfica e arte em comunidades pobres no município de Porto Nacional, Tocantins, Brasil|

| Carolina Machado Rocha Busch Pereira | Denis Ricardo Carloto |

A cidade por muito tempo imersa numa temporalidade lenta conservou algumas tradições e paisagens temporalizadas e perceptíveis nos traços de linguagem, nas fachadas das casas, nas ruas, nos ritos, festas, lendas, no universo urbano existente no interior das antigas habitações, nos modos de vida e todo um legado social, cultural e simbólico na qual a cidade esteve inserida quase todo século XX enquanto região do Norte Goiano (PALACIN, 1994).

O arraial que deu origem a cidade de Porto Nacional liga-se a exploração do ouro do período colonial (GIRALDIN, 2002). Ponto de passagem entre o rio Tocantins e as minas, a cidade estabeleceu com este rio fortes relações, fundindo natureza e cultura. A relação entre a cidade e o rio é intima e instauradoura, fornecendo um quadro de trajetórias subjetivas e mitificadoras a dar elã à teia da memória (OLIVEIRA, 2004).

A escolha dos bairros e comunidades foi realizada conjuntamente com a Secretaria de Desenvolvimento Social do município que é o órgão responsável pelo cadastro da população em Programas Sociais. Foram planejadas e executadas atividades didáticas pedagógicas para o ensino de Geografia com a utilização de música, pintura, cinema e outras manifestações artísticas. As atividades foram realizadas em dois CRAS - Centro de Referência da Assistência Social na cidade de Porto Nacional. Um CRAS localizado na região central e outro na região sul. O cadastramento e seleção dos participantes foram realizados por cada CRAS.

\section{Procedimentos metodológicos}

Os adolescentes que participaram do projeto foram selecionados pela Secretaria de Desenvolvimento Social do município de Porto Nacional a partir do Cadastro Único de Programas Sociais - CadÚnico que reúne todas as famílias participantes dos programas de transferência de renda do Brasil, parcela mais pobre da população.

As atividades foram desenvolvidas em oficinas culturais elaboradas pelo grupo composto de professores e estudantes de graduação em Geografia da Universidade Federal do Tocantins (UFT).

A escolha de trabalhar e direcionar o projeto para jovens pobres do município de Porto Nacional se justificava pela exclusão social e cultural própria do município. Muitos dos jovens filhos de beneficiários do Programa Bolsa Família não têm acesso ao cinema, nem tampouco as outras manifestações artísticas e culturais que não sejam as oriundas da televisão. Não há cinema e nem teatro na cidade de Porto Nacional, e as apresentações 
| Educação geográfica e arte em comunidades pobres no município de Porto Nacional, Tocantins, Brasil|

| Carolina Machado Rocha Busch Pereira | Denis Ricardo Carloto |

musicais são raras e escassas. A oferta de lazer para a população fica restrita ao período de praia (considerando que a cidade está localizada na margem direita do Tocantins, no período de julho - mês de férias escolares e época de altas temperaturas e baixa umidade a localidade realiza temporada de praia).

\section{O ENSINO DE GEOGRAFIA, AS PRÁticAS CULTURAIS E A RELAÇÃo COM A CIDADE}

A Geografia Escolar tem como pressuposto formar cidadãos críticos, conscientes e capazes de compreender a dinâmica do momento atual e a construção do espaço geográfico a partir dos sistemas de objetos e ações (SANTOS, 1996). O sujeito tem uma participação na organização do espaço geográfico e isso precisa ser compreendido no escopo da educação geográfica.

Para Libâneo (1992, p. 51), “a escola é mediadora entre o aluno e o mundo da cultura e cumpre esse papel pelo processo de transmissão e assimilação critica dos conhecimentos, inseridos no movimento da prática social concreta dos homens, que é objetiva e histórica"

Nesta perspectiva, Cavalcanti (2002, p.33) coloca que "a escola é um lugar de encontro de culturas, de saberes, de saberes científicos e de saberes cotidianos, ainda que o seu trabalho tenha como referência básica os saberes científicos”. Dessa forma, a escola é um espaço de miscigenação e mediação a diferentes manifestações culturais e sociais, envolvendo várias realidades distintas, que através da geografia escola e práticas desenvolvidas por docentes as especialidades cotidianas em seu mundo vivido tornam-se mais amplas e constroem assim, os conhecimentos de caráter científico.

Enquanto mediadores da construção do raciocínio crítico e geográfico, professores podem utilizar diferentes metodologias e distintas linguagens que proporcionem aos estudantes entenderem a dinâmica do espaço geográfico e as implicações que as ações humanas, escolhas e determinações provocam na relação do homem com a natureza, a partir de outro enfoque que não o livro didático, textos e os aparatos convencionais da escola.

Partindo deste pressuposto as questões que valorizam o cotidiano são consideradas de suma importância no processo de ensino e aprendizagem dos conceitos geográficos, pois a relação com o lugar de vivência é assumido a partir da imbricação com o mundo. 
| Educação geográfica e arte em comunidades pobres no município de Porto Nacional, Tocantins, Brasil|

|Carolina Machado Rocha Busch Pereira | Denis Ricardo Carloto|

Cavalcanti (2007, p. 25), ao discorrer sobre a relação entre cidade e vida cotidiana, destaca que a cidade é um lugar complexo, de produção social, de vida pública e coletiva. Logo, é um espaço “de contato, de resistência e de exclusão, em que há manifestação de diferentes percepções, usos, culturas e aspirações de distintos grupos, em seus espaços públicos e privados”. Entendida sob esta perspectiva, a cidade pode, portanto, ser pensada como um território, ou como territórios, territorialidades.

Segundo Raffestin (1993), ao se identificarem com algum espaço urbano, determinados grupos sociais se apropriam dele, concreta ou abstratamente, produzindo lugares específicos para tipos específicos de convivência, tornando-o cada vez mais fragmentado.

Desse ponto de vista, portanto, Cassab (2010) acrescenta que as experiências cotidianas de sujeitos desiguais tidas com o espaço urbano - os quais disputam o seu uso e apropriação, confrontando-se pelos seus direitos -, criam mecanismos fortemente marcados por processos de distinções, desigualdades e diferenciações no uso e apropriação da cidade.

Dentre esses sujeitos, destacam-se os jovens como produtores do espaço urbano e da cidade na qual vivem. Cabe ressaltar que essa produção se dá por meio da materialização de suas práticas cotidianas permeadas por suas representações, símbolos, interesses, relações sociais e culturais que, por sua vez, criam sobre o espaço territorializações, as quais representam a apropriação desse espaço e são o resultado das territorialidades desses jovens.

\section{RESULTADOS E DISCUSSÃO}

Do contato com as atividades realizadas com pinturas, poemas, músicas e cinema selecionamos duas, as quais nos detivemos para relatar a experiência e analisar os resultados. Trata-se do trabalho desenvolvido com poesias e pinturas que tinham a temática urbana como centro das composições e com a troca fecunda entre essas duas formas de expressão. Assim, pinturas geraram poesias e poesias geraram pinturas, multiplicando as linguagens pelas quais a cidade pode ser vista e lembrada.

O foco do trabalho desenvolvido, e que norteou as oficinas, foi a temática "cidade" e, a partir das reflexões, poesias, imagens, cinema e música abriram espaço para o debate sobre o sentido do urbano, da vida cotidiana e das relações existentes no espaço geográfico. 
| Educação geográfica e arte em comunidades pobres no município de Porto Nacional, Tocantins, Brasil|

| Carolina Machado Rocha Busch Pereira | Denis Ricardo Carloto |

Uma questão central orientou o debate: O que é a cidade? Uma questão simples de ser formulada, mas com alto grau de complexidade na reflexão. Uma questão complexa que exige certo esforço teórico, pois, para responder de forma satisfatória o que é a cidade na atualidade muitas vezes é preciso recuperar a sua história e passar pelas transformações tanto conceituais quanto formais e funcionais sofridas por ela. Entretanto, como a vivência urbana estende-se largamente na contemporaneidade, sabemos por experiência cotidiana o que é uma cidade. Transformar essa experiência numa compreensão do que seja a cidade, os seus problemas e potencialidades, assim como representá-los foram às maneiras buscadas nas oficinas culturais de pintura e poesia para atingir definições lúdicas e criativas sobre a cidade.

Olhar uma tela que tenha o urbano como tema central e escrever um poema do que é visto ou desenhar a cidade nele contida é entrecruzar olhares e dobrar a linguagem, nesse percurso do olhar sobre a cidade, muitas cidades se desenham, uma complementando a outra ou se conectando a outra. À maneira da feitura de tapetes, quando a trama termina uma cidade permanece: à cidade de todos os dias, àquela que nos pertence cotidianamente à qual debruçamos nossa experiência-vivência.

A cidade cotidiana que habitamos é o lugar onde estabelecemos uma identidade e reafirmamos nosso pertencimento, contudo, é também o lugar onde o hábito ofusca os detalhes, as nuances e as especificidades da paisagem.

As poesias utilizadas no projeto e nas oficinas foram de autores brasileiros, alguns reconhecidos nacionalmente como Mário de Andrade com o poema "Quando eu morrer quero ficar", e Carlos Drummond de Andrade com o poema "Cidadezinha qualquer" e outros poemas de autores pouco conhecidos como Albano Martins com o poema "Uma cidade" e Francisco de Britto com "Cidade antiga".

\section{Quando eu morrer quero ficar Mário de Andrade \\ Quando eu morrer quero ficar Quando eu morrer quero ficar, Não contem aos meus inimigos, Sepultado em minha cidade, Saudade. \\ Meus pés enterrem na rua Aurora, No Paissandu deixem meu sexo, $\mathrm{Na}$ Lopes Chaves a cabeça Esqueçam.}


| Educação geográfica e arte em comunidades pobres no município de Porto Nacional, Tocantins, Brasil|

| Carolina Machado Rocha Busch Pereira | Denis Ricardo Carloto |
No Pátio do Colégio afundem
O meu coração paulistano:
Um coração vivo e um defunto Bem juntos.

Escondam no Correio o ouvido Direito, o esquerdo nos Telégrafos,

Quero saber da vida alheia, Sereia.

O nariz guardem nos rosais, A língua no alto do Ipiranga Para cantar a liberdade.

Saudade...

Os olhos lá no Jaraguá Assistirão ao que há de vir, O joelho na Universidade, Saudade...

As mãos atirem por aí, Que desvivam como viveram, As tripas atirem pro Diabo, Que o espírito será de Deus. Adeus.

\section{Cidadezinha qualquer}

Carlos Drummond de Andrade

Casas entre bananeiras mulheres entre laranjeiras pomar amor cantar.

Um homem vai devagar. Um cachorro vai devagar. Um burro vai devagar. Devagar... as janelas olham.

Êta vida besta, meu Deus.

Que cidade está expressa nos poemas? Quais características são facilmente percebidas pelos alunos ao ler o poema? Os espaços físicos e psicológicos das narrativas são facilmente identificados? O tempo cronológico e histórico é reconhecido? Essas foram algumas das perguntas provocativas realizadas durante as oficinas e que permitiram um trabalho fecundo e inédito para aquelas crianças e adolescentes. As perguntas geradoras do debate costuravam o ensino de Geografia com a arte e aos poucos o trabalho de leitura de imagens e interpretação de texto foi gerando conhecimento. 
| Educação geográfica e arte em comunidades pobres no município de Porto Nacional, Tocantins, Brasil|

|Carolina Machado Rocha Busch Pereira | Denis Ricardo Carloto |

Somadas aos poemas, as pinturas (Figuras 2, 3, 4 e 5) permitiram um trabalho que primou desde o inicio à interlocução da Geografia com outras formas de ver, pensar e expressar a cidade. Seguem algumas das imagens utilizadas no projeto e nas oficinas com obras de arte de pintores brasileiros que retrataram a cidade em diferentes épocas e de diferentes maneiras.

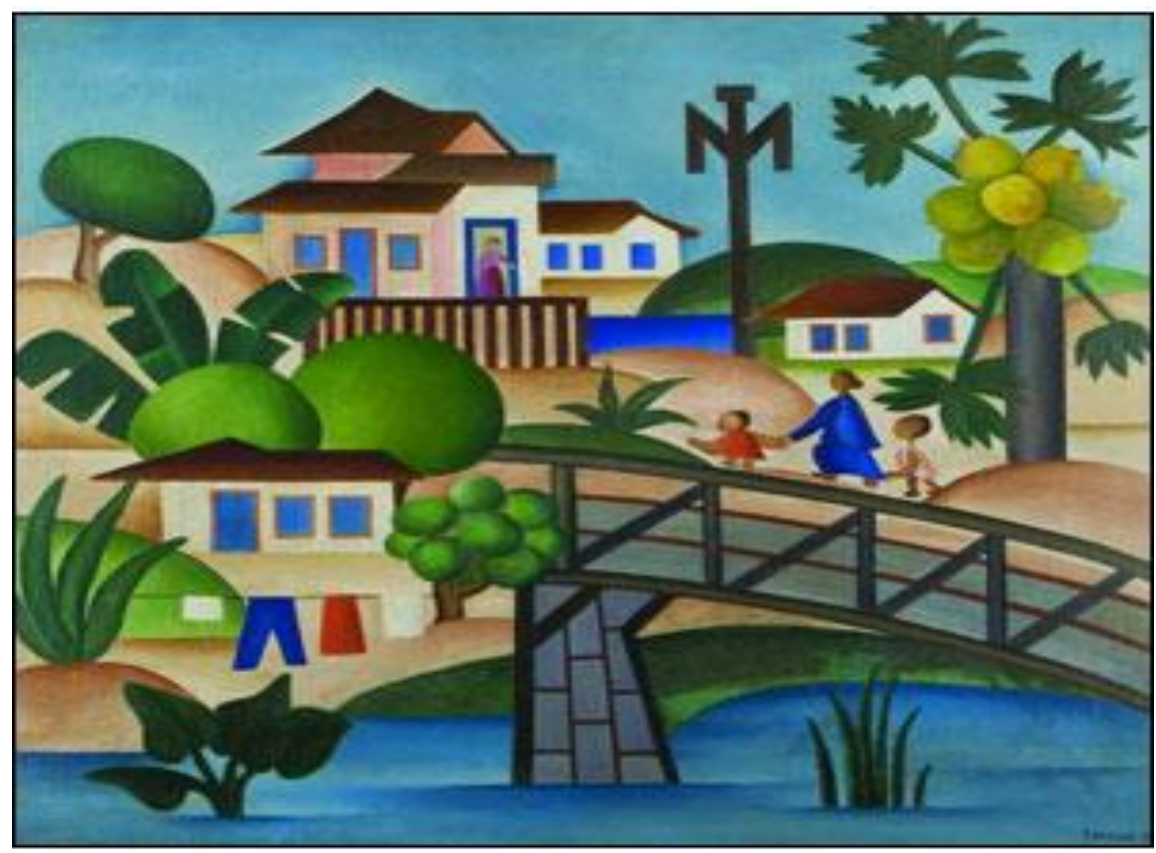

Figura 2 - O Mamoeiro - Tarsila do Amaral - 1925. Óleo sobre tela $(65$ x $70 \mathrm{~cm})$. Fonte: Coleção de Artes Visuais do Instituto de Estudos Brasileiros - USP (São Paulo, SP).

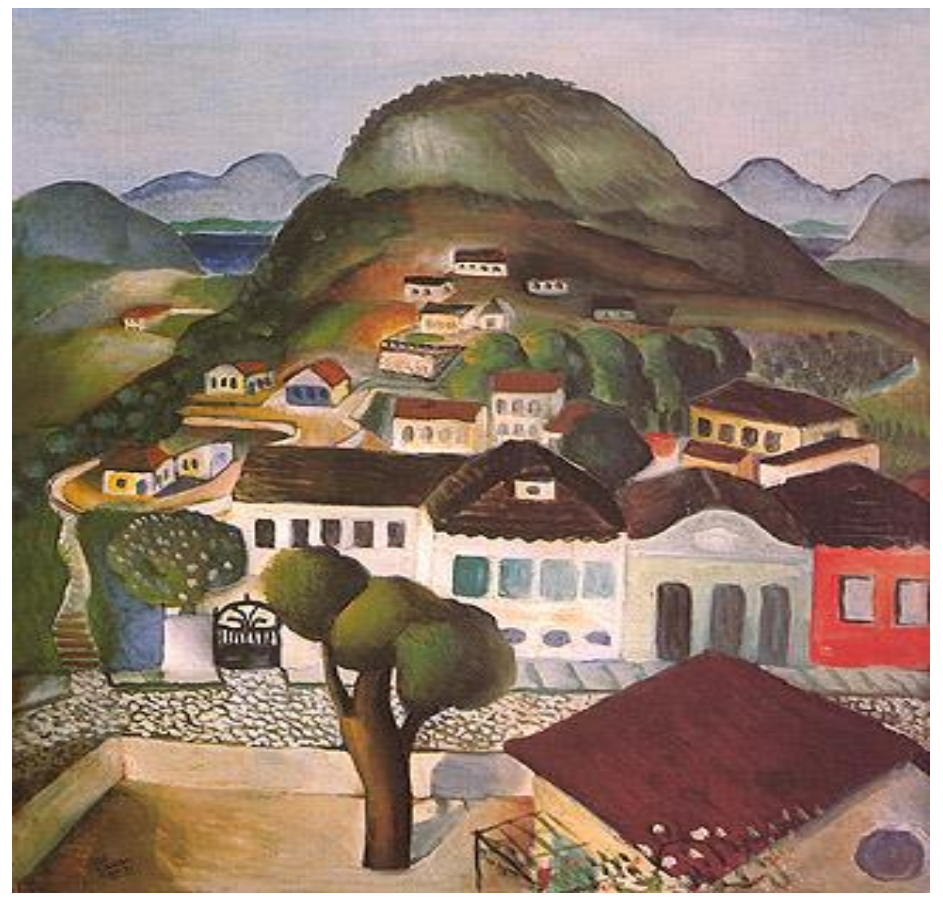

Figura 3 - Paisagem de Subúrbio - Di Cavalcanti - 1930. Óleo sobre tela (61 x 50 cm). Fonte: Coleção Maria do Carmo. 
|Educação geográfica e arte em comunidades pobres no município de Porto Nacional, Tocantins, Brasil|

|Carolina Machado Rocha Busch Pereira | Denis Ricardo Carloto|

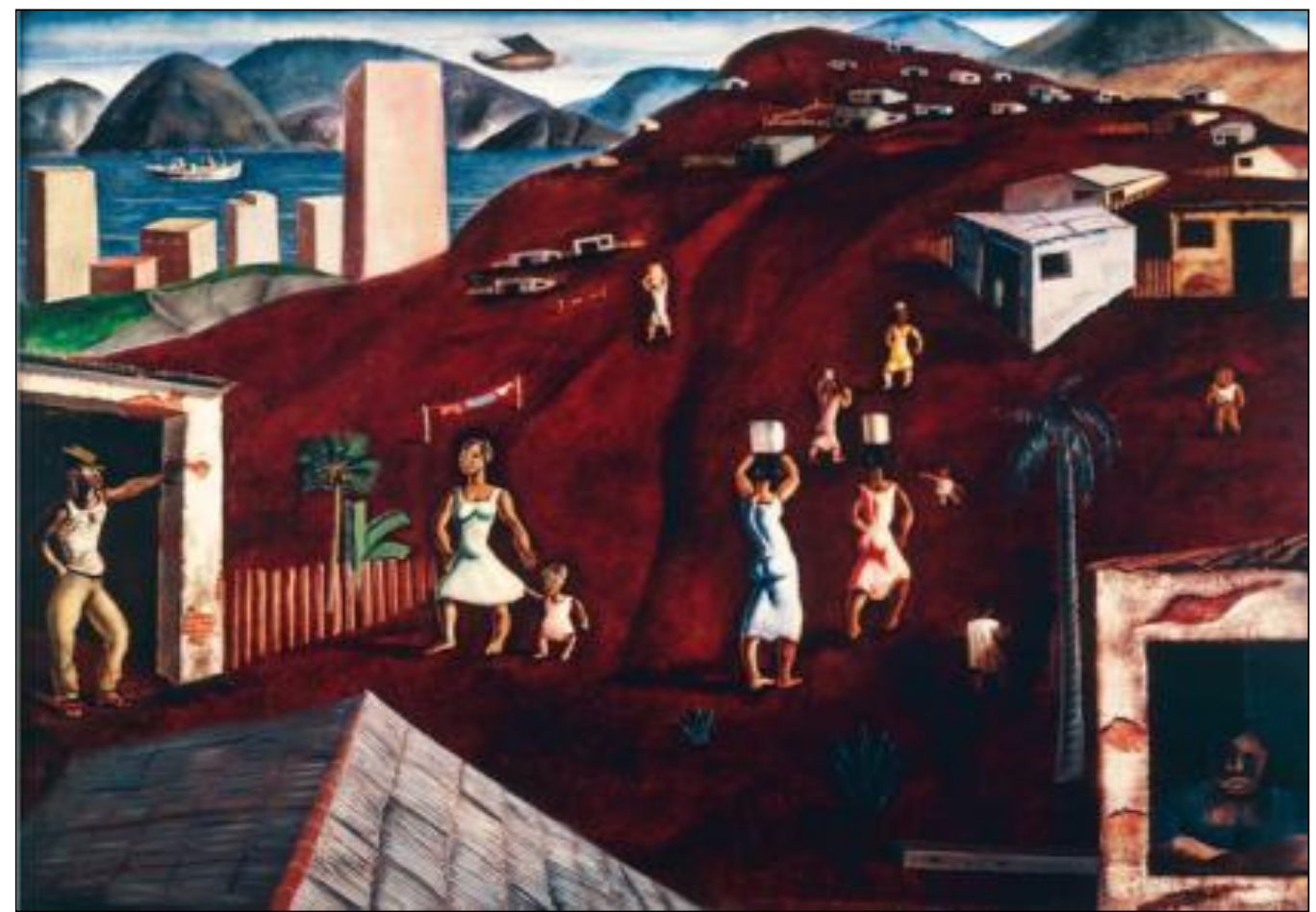

Figura 4 - Morro - Candido Portinari - 1933. Óleo s/ madeira (114 x $146 \mathrm{~cm})$. Fonte: Telecentro Casa da Cultura/Rio de Janeiro - RJ.

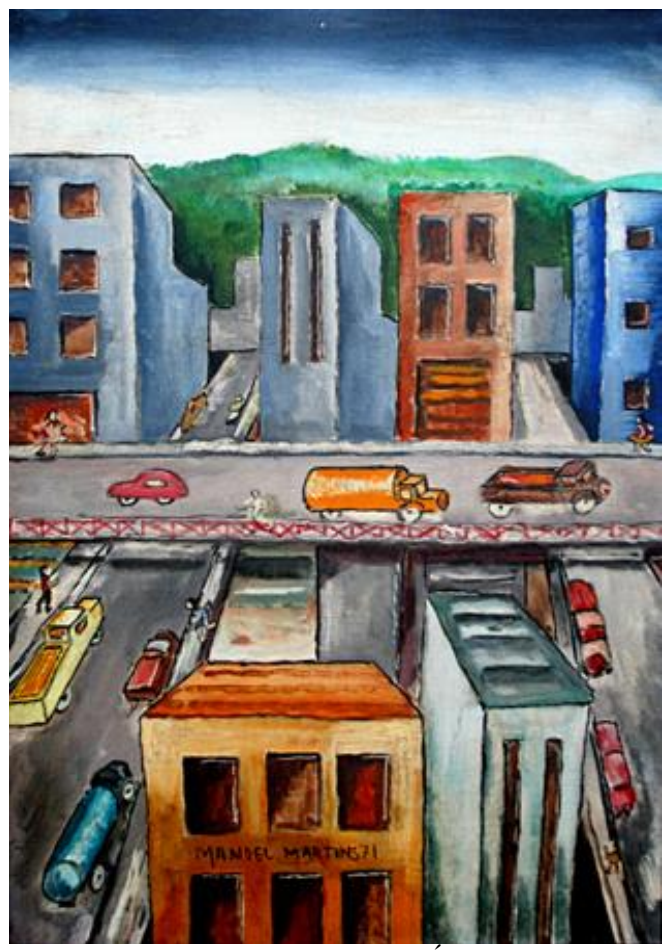

Figura 5 - Cidade - Manoel Martins - 1971. Oleo sobre tela $(46.5$ x $33 \mathrm{~cm})$. Fonte: Série: Cidade

Os quadros (Figuras 2, 3, 4 e 5) e os poemas previamente selecionados foram impressos em papel A4 com as devidas referências de local e acervo, data da obra, características da pintura, tamanho e um breve histórico do pintor. 
| Educação geográfica e arte em comunidades pobres no município de Porto Nacional, Tocantins, Brasil|

| Carolina Machado Rocha Busch Pereira | Denis Ricardo Carloto |

As oficinas tiveram como objetivo despertar o olhar e a criticidade dos alunos frente às pinturas e poemas sobre a cidade e proporcionar um entendimento sobre a cidade vista por diversas formas de linguagens que não apenas o texto escrito - verbal. A ideia era apresentar aos jovens um texto não verbal com os poemas e as imagens, e a partir deste enfoque refletir sobre a importância da arte como manifestação cultural e artística e como arte reflete e exprime a realidade cotidiana. A cidade não é pensada somente pelos planejadores mas por todos que de alguma maneira expressam as angustias, os desejos, as vontades e as recusas.

De posse das impressões das pinturas e dos poemas, debatemos sobre os autores das obras de arte, o período em que foram feitos, contextualizando desta maneira o espaço e o tempo em uma obra artística. Os jovens em grupo, escolheram aleatoriamente uma pintura, e de posse desta construiriam uma poesia. Tiveram aproximadamente uma hora para construir a poesia. Para finalizar esta atividade, as duplas apresentaram a pintura escolhida e leram os poemas para os demais participantes, destacando o que mais chamou a atenção dos mesmos no quadro escolhido. Ao longo da apresentação indagávamos sobre suas escolhas e questionávamos sobre a relação da cidade pintada e contada com a realidade local do município de Porto Nacional. Esta oficina teve uma duração de aproximadamente duas horas.

Após esta etapa, invertemos as atividades: os jovens escolheram uma poesia dentre as muitas disponíveis e impressas previamente e de posse da poesia a dupla construiu um desenho em papel ou uma pintura em tela, buscando representar a poesia.

Após a conclusão desta etapa, os alunos apresentaram o poema escolhido e logo em seguida apresentavam a pintura realizada. As duas oficinas somaram quatro horas que foram vivencias numa tarde.

As pinturas e as poesias utilizadas nas oficinas e durante todo o projeto são de artistas brasileiros de diferentes décadas, mas todas possuem a temática urbana como cerne do trabalho.

Os debates envolveram os jovens que mostraram em diversas ocasiões interesse pelas obras de arte que estavam sendo apresentadas pela primeira vez a eles. Muitos foram os jovens que elogiaram a iniciativa do projeto e destacaram a importância da ação.

Poucos jovens conheciam as obras de arte, apesar de muitas delas serem nacionalmente conhecidas. Mas para aqueles jovens pobres e moradores da periferia da cidade, aquele universo artístico era totalmente desconhecido. 
| Educação geográfica e arte em comunidades pobres no município de Porto Nacional, Tocantins, Brasil|

| Carolina Machado Rocha Busch Pereira | Denis Ricardo Carloto |

Finalizamos o projeto com um total de 164 jovens atendidos em oficinas culturais e capacitamos sete alunos de graduação para trabalhar como monitores nas oficinas.

Para alcançar os objetivos do projeto foram realizadas pesquisas bibliográficas, orientações, reuniões de equipe para planejamento e desenvolvimento das atividades e visita aos locais onde foram ministradas as oficinas.

\section{CONSIDERAÇÕES FINAIS}

Aproximar os jovens atendidos por programas sociais dos alunos de graduação da UFT foi uma oportunidade de aproximar a Universidade da comunidade, e, além de realizar um trabalho social, o aspecto educativo esteve presente durante a realização do projeto.

Um aspecto relevante do projeto foi a oportunidade de apresentar aos jovens a ciência geográfica enquanto produtora de conhecimento, capaz de compreender a cidade em que vivem e poder pensar, planejar e executar ações. Com gestão democrática, acessibilidade, cuidados com a população entre outras ações cidadãs.

Durante a realização do projeto não houve rejeição às atividades pelos jovens, não houve evasão em nenhum momento, demonstrando a aceitação por parte dos envolvidos. O trabalho sobre a cidade realizado nas linhas e entrelinhas dos poemas, das imagens, das músicas e dos filmes foi satisfatório.

Sobre a percepção da cidade que os jovens manifestavam durante as oficinas era expressa pelo desejo de ter na cidade, áreas destinadas ao lazer, espaços livres com oferta de atividades de esporte, cultura e entretenimento. Uma cidade organizada sob a lógica da cidadania, da justiça social e do direito de todos.

Aprendizado e encontro são duas palavras que podem traduzir de algum modo a tessitura de linguagens empreendidas e pelas quais a cidade foi redesenhada.

\section{REFERÊNCIAS}

ABREU, Maurício de Almeida. Sobre a memória das cidades. Revista da Faculdade de Letras da Universidade do Porto, v. XIV, p. 77-97, 1998. Disponível em <http://ler.letras.up.pt/uploads/ficheiros/1609.pdf>. Acesso em: 19 jun. 2016.

CASSAB, Clarice. Os jovens e a cidade: relações e representações. Revista de Geografia, Recife: UFPE - DCG/NAPA, v. 27, n. 1, jan./abr. 2010. Disponível em: < http://www.ufpe.br/revistageografia/index.php/revista/article/viewFile/228/184>. Acesso em: 25 set. 2012. 
CAVALCANTI, Lana de Souza. Cidade e Vida Urbana: a dinâmica do/no espaço intraurbano e formação para a participação em sua gestão. In: PAULA, Flávia Maria de Assis; CAVALCANTI, Lana de Souza (Org.). A cidade e seus lugares. Goiânia: Vieira, 2007.

Geografia e prática de ensino. Goiânia: Alternativa, 2002.

GIRALDIN, Odair. Pontal e Porto Real: dois arraiais do norte de Goiás e os conflitos com os Xerente nos século XVIII e XIX. Revista Amazonense de História, v. 1, n.1, p. 131 146, jan./dez. $2002 . \quad$ Disponível em $<$ http://www.uft.edu.br/neai/file/odair pontal porto real.pdf $>$. Acesso em: 20 jun. 2016.

GRUNBERG, Evelina. Manual de atividades práticas de educação patrimonial. Brasília: IPHAN, 2007.

HOBSBAWM, Eric. Sobre História. São Paulo: Companhia das Letras, 1997.

IPHAN. Instituto do Patrimônio Histórico e Artístico Nacional. Dossiê de Tombamento do Centro Histórico de Porto Nacional - TO. Porto Nacional: Centro Histórico de Porto Nacional: Notícia e História, 2007.

LE GOFF, Jacques. Documento/Monumento. In: História e Memória. 3 ed. Campinas: Editora da Unicamp, 1994.

LIBÂNEO, José Carlos. A Democracia da Escola Pública. Rio de Janeiro: Paz e Terra, 1992.

MORICONI, Ítalo (Org.). Os cem melhores poemas brasileiros do século. Rio de Janeiro: Objetiva, 2001.

OLIVEIRA, Maria de Fátima. Um porto no sertão. In: GIRALDIN, Odair (Org.). A (trans) formação histórica do Tocantins. 2. ed. Goiânia: Ed. UFG, 2004, p. 237-286.

PALACIN, Luís. O século do ouro em Goiás: 1722-1822 estrutura e conjuntura numa capitania de minas. 4. ed. Goiânia: Ed. UCG, 1994.

RAFFESTIN, C. Por uma Geografia do poder. São Paulo: Ática, 1993.

SANTOS, Milton. A natureza do espaço. Técnica e tempo. Razão e Emoção. Hucitec: São Paulo, 1996. 